\title{
KLOTHO polymorphisms in the elderly population from the Sao Paulo Ageing \& Health Study
}

\author{
Thiago Quadrante Freitas ${ }^{1}$,André Silva Franco ${ }^{1}$, Isac de Castro ${ }^{2}$, Rosa Maria Rodrigues Pereira ${ }^{1}$
}

$\mathrm{T}$ The KLOTHO gene was discovered in 1997 when its defective expression in mice led to a syndrome that resembles human ageing, including a short lifespan, arteriosclerosis, and osteoporosis ${ }^{1}$. Its byproduct exists as a secreted protein ${ }^{2}$ and as a transmembrane protein expressed predominantly in the distal tubules of the kidney, choroid plexus, and pituitary gland[1], having unknown function in humans. The secreted form suppresses oxidative stress and growth factor signaling, including insulin/IGF-1 signaling, which is associated with longer life span. In fact, studies in human populations attempted to show associations between a functional variant of Klotho, called "KL-VS", which has six polymorphisms in linkage disequilibrium, and aging/longevity ${ }^{3}$.

At this moment, at least 10 mutations and singlenucleotide polymorphisms (SNPs) were described in humans; $395 \mathrm{G}>\mathrm{A}$ and $1818 \mathrm{C}>\mathrm{T}$ are the most common $\mathrm{SNPs}^{4}$. Nonetheless, the effects of each SNP in human ageing is still obscure.

Associations between specific KLOTHO SNPs and age-related outcomes were demonstrated in different populations. The $395 \mathrm{G}>$ A polymorphism was associated with blood pressure levels in Korean women, and the 1818 $\mathrm{C}>\mathrm{T}$ polymorphism with fasting plasma glucose in the same population ${ }^{5}$. In Japanese men, both SNPs correlated to body-fat ratio and to HDL cholesterol levels; and in Japanese women, to fasting glucose, bone mineral density and systolic blood pressure ${ }^{6}$.

In Brazilian population there are no studies regarding KLOTHO polymorphisms and age-related comorbidities. Hence, our group seeks to evaluate three KLOTHO gene polymorphisms in an elderly population from the Sao Paulo Ageing \& Health Study (SPAH) and their potential association with the prevalence of senilityrelated outcomes.

\section{REFERENCES}

1. Kuro-o M, Nabeshima Y, Matsumura Y, Aizawa H, Kawaguchi $\mathrm{H}$, Suga T, et al. Mutation of the mouse Klotho gene leads to a syndrome resembling ageing. Nature. 1997;390(6655):45-51. Available from: doi: 10.1038/36285.

2. Xu X, Liang X, Hu G, Zhang J, Lei H. Renal function and Klotho gene polymorphisms among Uygur and Kazak populations in Xinjiang, China. Med Sci Monit. 2015;21:4451. doi: 10.12659/MSM.891213.

3. Di Bona D, Accardi G, Virruso C, Candore G, Caruso C. Association of Klotho polymorphisms with healthy aging: a systematic review and meta-analysis. Rejuvenation Res. 2014;17(2):212-6. doi: 10.1089/rej.2013.1523.

4. Shimoyama Y, Taki K, Mitsuda Y, Tsuruta Y, Hamajima N, Niwa T. KLOTHO gene polymorphisms G-395A and C1818T are associated with low-density lipoprotein cholesterol and

Award Panels Clinical COMU 2017 - XXXVI Congresso Médico Universitário da FMUSP, São Paulo, 6-8 out. 2017.

1- Bone Metabolism Laboratory, Rheumatology Division, Faculdade de Medicina, Universidade de Sao Paulo, Sao Paulo, SP, BR.

2- Biostatistician.

Corresponding address: Av. Dr. Arnaldo, 455, 3rd floor, room 3193. Sao Paulo, SP, BR. CEP: 01246-903. E-mail: thiago.f@fm.usp.br. 
Freitas TQ, et al. KLOTHO polymorphisms in the elderly population.

uric acid in Japanese hemodialysis patients. Am J Nephrol. 2009;30(4):383-8. doi: 10.1159/000235686.

5. Rhee EJ, Oh KW, Lee WY, Kim SY, Jung CH, Kim BJ, et al. The differential effects of age on the association of KLOTHO gene polymorphisms with coronary artery disease. Metabolism. 2006;55(10):1344-51. doi: 10.1016/j.metabol.2006.05.020.
6. Shimoyama Y, Nishio K, Hamajima N, Niwa T. KLOTHO gene polymorphisms G-395A and C1818T are associated with lipid and glucose metabolism, bone mineral density and systolic blood pressure in Japanese healthy subjects. Clin Chim Acta. 2009;406(1-2):134-8. doi: 10.1016/j.cca.2009.06.011.

Submitted for publication: June 18, 2018

Accepted in: June 21, 2018 